\title{
Transient early wheeze is not associated with impaired lung function in 7-yr-old children
}

\author{
S. Lau*, S. Illi*\#, C. Sommerfeld*, B. Niggemann*, K. Völkel*, C. Madloch*, C. Grüber*, R. Nickel*, \\ J. Forster", U. Wahn*, and the Multicentre Allergy Study Group
}

Transient early wheeze is not associated with impaired lung function in 7-yr-old children. S. Lau, S. Illi, C. Sommerfeld, B. Niggemann, K. Völkel, C. Madloch, C. Grüber, R. Nickel, J. Forster, U. Wahn, and the Multicentre Allergy Study Group. (C) ERS Journals Ltd 2003.

ABSTRACT: The aim of the present study was to analyse determinants of lung function in 7-yr-old children with different wheezing patterns (early, persistent and late onset) in a prospective cohort study.

The German Multicentre Allergy Study (MAS) followed 1,314 children from birth onwards. Annual assessments included clinical check-ups, a structured interview and repeated measurement of specific immunoglobulins $\operatorname{Ig}(E)$ directed against food and inhalant allergens. At the age of $7 \mathrm{yrs}$, lung function was measured by body plethysmography in 800 children.

Episodes of wheezing in the past 12 months ("current wheeze") were strongly associated with reduced lung function at age $7 \mathrm{yrs}$. Children with wheezing episodes only during the first 3 yrs of life showed a slight impairment in maximal expiratory flow when $50 \%$ of the forced vital capacity remains to be exhaled $(98.9 \pm 24.2$ versus $103.2 \pm 22.8 \%$ of the predicted value in children who never wheeze). Separate analysis of determinants of pulmonary function within these subgroups resulted in distinctly different patterns. Determinants of impaired lung function in the group of current wheezers were: time in years since first wheeze, a parental history of atopy, current sensitisation to indoor allergens, elevated cord blood IgE levels and a low ponderal index at birth. In the group of transient early wheezers, frequent lower respiratory tract infections early in life and maternal smoking during pregnancy were significant but weak determinants of impaired lung function.

The present results indicate that determinants of pulmonary function in 7-yr-old children differ with respect to different wheezing phenotypes, demanding different therapeutic strategies. Although transient early wheezers were found to have normal-tosubnormal lung function, children with asthmatic symptoms (persistent and late-onset disease) at age 7 yrs already show significant impairment of expiratory flow volumes. Eur Respir J 2003; 21: 834-841.

\author{
*Dept of Paediatric Pneumology and Immuno- \\ logy, Charité, Humboldt University, Berlin, \\ \#University Children's Hospital von Hauner, \\ Munich, and 'University Children's Hospital, \\ Freiburg, Germany.
}

Correspondence: S. Lau

Dept of Paediatric Pneumology and Immunology Charité

Humboldt University

Augustenburger Platz 1

D-13353 Berlin

Germany

Fax: 4930450566931

E-mail: susanne.lau@charite.de

Keywords: Asthma in childhood prospective cohort study

pulmonary function

wheezing

Received: May 42002

Accepted after revision: December 62002

The Multicentre Allergy Study (MAS) was supported by the German Ministry of Education and Research (Bonn, Germany), grant number 01 EE9406.
Asthma and wheezing represent an increasing proportion of acute and chronic illness in childhood. Over the past $5 \mathrm{yrs}$, various phenotypes of wheezing and asthma have been described, showing different outcomes with respect to pulmonary function. Although children with wheezing episodes during the first 3 yrs of life but not at age 6 yrs have been found to have diminished airway function both before the age of $1 \mathrm{yr}$ and at the age of 6 yrs, children with onset of obstructive airway disease after their third birthday and children with wheezing episodes before and after their third birthday showed significant impairment of lung function at school age [1, 2].

There are reports that low birthweight and maternal smoking during pregnancy may influence lung growth and therefore be associated with lower forced vital capacity (FVC) [3-5] and later asthma or respiratory disease [6-8]. Conversely, increased foetal growth was reported to be related to increased risk of asthma and atopy in childhood [9]. Children with early lower respiratory tract infections such as respiratory syncytial virus-induced bronchiolitis were found to have diminished lung function later in life [10-12] and considered to be at risk of recurrent wheezing episodes [13, 14].

The aim of the present study was to investigate determinants of basic lung function in 7-yr-old schoolchildren with different patterns of wheezing (early, persistent and late-onset disease) in a large prospective cohort study in order to identify children at risk of early impairment of expiratory flows.

\section{Methods}

\section{Study design}

In the German Multicentre Allergy Study (MAS), 1,314 newborns were recruited in five West-German cities during 1990. A detailed description of study subjects and methods is provided elsewhere [15]. The mothers $(6,019 ; 79 \%)$ and fathers $(5,819 ; 77 \%)$ of 7,609 infants born in six obstetric departments in the five cities (Berlin, Munich, Mainz, Düsseldorf and Freiburg) between January-December 1990 filled in the questionnaire. According to the questionnaire, $22 \%$ of the mothers and $21 \%$ of the fathers were classified atopic. Of the families invited, 64\% participated in the study: 499 infants with a double-positive family history and/or cord blood immunoglobulin (Ig)E levels of $>0.9 \mathrm{kU} \cdot \mathrm{L}^{-1}$ (all at-risk infants available) 
were recruited as cases and 815 infants, who were simultaneously selected at random from the remaining newborns, participated as infants at random risk.

The study was approved by the local ethics committee. Parents gave informed consent. The cohort children were followed up at the age of 1, 3, 6, 12 and 18 months and from then on annually within 3 months of the child's birthday up to the age of $7 \mathrm{yrs}$. If parents agreed, blood samples were collected from the children. At the age of $7 \mathrm{yrs}$, lung function was assessed.

\section{Parental questionnaire}

At each follow-up visit, parents took part in structured interviews with a study doctor focusing particularly on the asthmatic or atopic symptoms of the child. At the age of 7 yrs, the International Study of Asthma and Allergies in Childhood questionnaire was used for the assessment of asthma [16]. Parents were asked whether the child had ever had a "wheezing or whistling noise in the chest while breathing" and whether the child had wheezed during the 12 months prior to the interview. "Current wheeze" was defined as at least one episode of wheezing during the 12 months prior to the interview ( 93 of 939 children). Children were considered "persistent wheezers" if they had reported episodes of wheezing before the age of 3 yrs and during the seventh year of life $(n=39)$. Children were considered "early transient wheezers" if they had reported episodes of wheezing during the first 3 yrs of life but not at age 7 yrs $(n=200)$. Children with no wheezing episodes before the third birthday but at age 7 yrs were considered "late-onset wheezers" $(n=42)$. Parents were also asked whether a doctor had ever diagnosed asthma, hay fever or eczema. Severity of wheezing illness was assessed using different questions regarding "number of wheezing episodes", "awakening due to wheeze", "speech-limiting wheeze", "wheeze with exercise" and "wheeze with colds".

Furthermore, several questions covered previous infections (lower and upper respiratory tract) and environmental exposures, such as maternal smoking during pregnancy and postnatal environmental tobacco smoke exposure. The ponderal index at birth was calculated (weight in kilograms/ (height in metres) ${ }^{3}$ ). Parental history of atopy (asthma, hay fever or eczema), number of older siblings (defined as number of previous deliveries) and social status according to the secondary education of both parents (low, medium or high) were assessed at birth. Parents were considered atopic if they reported at least one of the following atopic disorders or relevant symptoms: atopic eczema; allergic rhinitis or asthma; and sensitisation to food, pollen, house dust mites, pets or moulds.

\section{Serum immunoglobulin E}

Serum samples were obtained from the children at birth and at 1, 2, 3, 5, 6 and 7 yrs of age. As described previously, cord blood IgE, total serum IgE and specific serum IgEs directed against hen-egg, cow's milk, soy and wheat and four inhalant allergens (house dust mite, cat dander, and mixed grasses and birch pollen) were determined by CAPradioallergosorbent test-fluorescence enzyme immunoassay (Pharmacia, Freiburg, Germany). Elevated cord blood IgE levels was defined as concentrations of $\geqslant 0.9 \mathrm{kU} \cdot \mathrm{L}^{-1}$. Since blood samples at the age of 7 yrs were not available for all participants, measurements from the previous study year were also considered in the definition of atopic sensitisation in order to maximise the number of children with measurements of specific IgE levels. Serum samples were available for a total of 768 children; 679 of these serum IgE samples were taken at age 7 yrs and 89 at age 6 yrs. Sensitisation to a specific allergen was defined as a concentration of $\geqslant 0.35 \mathrm{kU} \cdot \mathrm{L}^{-1}$ $(\geqslant$ CAP class 1$)$.

\section{Pulmonary function test}

Baseline lung function tests, i.e. expiratory manoeuvres and whole body plethysmography were performed according to the criteria of the European Respiratory Society [17] and the US National Heart, Lung and Blood Institute [18] using the same body plethysmographs in all study centres (Master-Lab; E. Jaeger, Würzburg, Germany). $\beta_{2}$-agonists were withdrawn for $\geqslant 12 \mathrm{~h}$ and sodium cromoglycate for $48 \mathrm{~h}$ prior to testing. No other drugs which might interfere with lung function were used by the children. Inhaled steroids were not withdrawn prior to testing. After measuring height and weight, a baseline lung function test was performed. Results are expressed as a percentage of the predicted value according to internal reference values. The parameters forced expiratory volume in one second (FEV1), FVC, maximal expiratory flow when 75, 50 and $25 \%$ of the FVC remains to be exhaled (MEF75\%, $\mathrm{MEF} 50 \%$ and MEF25\%), peak expiratory flow and effective airway resistance (Raw,eff) were measured and the FEV1/FVC ratio calculated.

\section{Statistics}

In order to identify potential determinants of baseline lung function, the distribution of values was analysed using the Wilcoxon rank-sum test in the case of binary variables and the Kruskal-Wallis test for variables with more than two categories as nonparametric tests and using the t-test as parametric test if values were normally distributed. All variables with a $p \leqslant 0.05$ in the bivariate analysis were considered covariates in a multivariate logistic regression analysis with the various lung function parameters (as a percentage of the predicted value) as the dependent variable. Multivariate analyses were adjusted for study centre and season. For continuous variables (time since first wheeze and ponderal index), the $\beta$-coefficient is given for the linear regression analysis, in order to measure the association between risk factor and outcome variable; $\beta>0$ implies that synergistic effect is likely and $\beta<0$ implies an antagonistic effect. $\mathrm{R}^{2}$ as the proportion of the variance explained by the variables in the regression model are given.

In order to calculate reference values for the present study population, healthy children with a negative history of asthma and wheezing were selected from the group of children who underwent lung function testing at age 7 yrs (600 of 800). Lung function parameter, height and weight were logarithmically transformed and included in a regression equation: ln lung function parameter $=\mathrm{ln} w \mathrm{t}+\log \mathrm{ht}$, where $\mathrm{wt}$ and ht are weight and height, respectively. Calculations were performed separately for males and females. For males, the final regression equations were $\ln \mathrm{FVC}=-9.435545+1.884565 \mathrm{ln} \mathrm{ht}+0.266976$ ln wt; ln FEV1=-8.176399+1.641604ln ht+0.214882ln wt; and $\ln$ MEF50\%-5.209169+1.237567ln ht. For females, the final regression equations were $\ln \mathrm{FVC}=-6.905281+1.309453$ $\ln \mathrm{ht}+0.325554 \ln \mathrm{wt} ; \ln \mathrm{FEV} 1=-6.836523+1.336647 \mathrm{ln} \mathrm{ht}+$ $0.240659 \ln w t$; and $\ln$ MEF50=-6.700993+1.542338ln ht.

\section{Results}

\section{Response rates and potential selection bias}

Of the 1,314 children in the MAS birth cohort, 939 (71.5\%) participated in the follow-up study at age $7 \mathrm{yrs}$, i.e. their 
Table 1. - Characteristics of study population and wheezing phenotypes

\begin{tabular}{|c|c|c|c|c|c|}
\hline & Never & Transient & Late & Persistent & p-value \\
\hline Age at testing yrs & $7.09 \pm 0.14(539)$ & $7.08 \pm 0.13(210)$ & $7.12 \pm 0.12(44)$ & $7.10 \pm 0.17(40)$ & $0.381^{\#}$ \\
\hline Gestation weeks & $40.00 \pm 1.39(593)$ & $39.88 \pm 1.68(230)$ & $40.15 \pm 1.21(46)$ & $39.96 \pm 1.43(47)$ & $0.616^{\#}$ \\
\hline Birthweight kg & $3.411 \pm 0.46(603)$ & $3.382 \pm 0.48(236)$ & $3.360 \pm 0.44(47)$ & $3.430 \pm 0.43(46)$ & $0.744^{\#}$ \\
\hline Family history of atopy & $299 / 606(49.3)$ & $133 / 237(56.1)$ & $33 / 47(70.2)$ & $37 / 47(78.7)$ & $<0.0001^{\uparrow} ;<0.0001^{+}$ \\
\hline Female sex & $308 / 606(50.8)$ & $105 / 238(44.1)$ & $20 / 47(42.6)$ & $20 / 47(42.6)$ & $0.216^{\oplus^{\prime}} ; 0.058^{+}$ \\
\hline Maternal smoking in pregnancy & $96 / 582(16.5)$ & $59 / 218(27.1)$ & $7 / 46(15.2)$ & $11 / 46(23.9)$ & $0.006^{\oplus} ; 0.047^{+}$ \\
\hline \multicolumn{6}{|l|}{ Parental smoking } \\
\hline At birth & $261 / 597(43.7)$ & $119 / 224(53.1)$ & $26 / 47(55.3)$ & $23 / 46(50.0)$ & $0.060^{\oplus} ; 0.034^{+}$ \\
\hline At testing & $20 / 602(36.5)$ & $18 / 238(49.6)$ & $4 / 47(51.1)$ & $4 / 47(51.1)$ & $0.001^{\oplus ; 0.0005^{+}}$ \\
\hline Any specific sensitisation & $152 / 429(35.4)$ & $75 / 176(42.6)$ & $28 / 37(75.7)$ & $25 / 37(67.6)$ & $<0.0001^{\uparrow} ;<0.0001^{+}$ \\
\hline Any inhalant sensitisation & $117 / 431(27.1)$ & $65 / 178(36.5)$ & $27 / 37(73.0)$ & $25 / 37(67.6)$ & $<0.0001^{\top} ;<0.0001^{+}$ \\
\hline
\end{tabular}

Data are presented as mean \pm SD (n) or number showing characteristic/number in sample (percentage). ${ }^{\#}$ : analysis of variance; ${ }^{\circ}$ : Chisquared test; ${ }^{+}$: Mantel-Haenszel test.

parents responded to the questionnaires and physical examination was performed. Of these 939 children, $800(85.2 \%)$ completed forced expiratory manoeuvres and body plethysmography. In order to assess potential participation bias, these 800 children were compared with all other children in the MAS birth cohort based on data collected at birth. Participants did not differ significantly from nonparticipants with respect to sex, parental history of atopy, cord-blood IgE levels, paternal smoking or number of older siblings (data not shown).

However, children of families of a lower social class were less likely to participate than children of middle or higher class (52.5 versus 63.3 and $65.5 \%$ respectively, $\mathrm{p}<0.003$ (Pearson Chi-squared test)).

At age $7 \mathrm{yrs}$, participating and nonparticipating children did not differ with respect to "doctor's diagnosis of asthma", prevalence of wheeze, sensitisation to indoor and outdoor allergens at age $7 \mathrm{yrs}$, pet ownership or presence of at least one smoking parent.

\section{Asthma and wheeze}

Of 800 children who underwent lung function testing, 50 $(6.3 \%)$ had a "doctor's diagnosis of asthma"; $81(10.1 \%)$ reported at least one episode of wheezing during the past 12 months ("current wheeze"); $200(25.0 \%)$ were found to have had at least one wheezing episode during the first 3 yrs of life but not at age 7 yrs ("transient early wheeze"); 42 $(5.3 \%)$ developed wheezing illness after the third year of life ("late-onset wheezers"); and $39(4.9 \%)$ reported wheezing episodes in the first 3 yrs and in the seventh year of life ("persistent wheezers"). Table 1 shows the characteristics of the study population, divided into nonwheezers and the three different wheezing groups. In the group of children who never wheezed, parental smoking was less frequent than in the three wheezing groups. Parental atopy was most frequent in the late-onset and persistent wheezer groups.

\section{Atopy}

Elevated levels of specific IgEs directed against inhalant allergens were found in 280 of $679(41.2 \%)$ children; 168 of $481(34.9 \%)$ children without history of wheezing; 79 of 193 $(40.9 \%)$ transient wheezers; 30 of $40(75.0 \%)$ late-onset wheezers and 28 of $41(68.3 \%)$ persistent wheezers.

\section{Persistent and late-onset wheezers}

Children with persistent wheeze showed the greatest reduction in FEV1 and MEF50\% and MEF25\% (table 2). MEF75\% was significantly reduced in persistent and late-onset wheezers $(93.8 \pm 20.2$ and $93.1 \pm 15.1 \%$ pred (mean \pm SD), $\mathrm{p}<0.05$ and $\mathrm{p}<0.001$ respectively) compared to nonwheezers $(102.2 \pm 20.2 \%$ pred). There was no significant difference in FVC in the wheezing subgroups compared to children without a history of wheeze. The Raw,eff was slightly increased only in the group of children with persistent and current wheeze $(122.8 \pm 32.8$ and $115.4 \pm 40.5$ versus $107.8 \pm 47.0 \%$ pred in nonwheezing children, $\mathrm{p}<0.05)$.

Children with transient early wheeze showed hardly any impairment in lung function at the age of 7 yrs (table 2).

Separate analysis of determinants of pulmonary function within the subgroups of wheezers resulted in distinctly different patterns (tables 3-5). Determinants of lung function in current wheezers (late-onset and persistent wheezers) were time in years since first wheeze, a parental history of atopy,

Table 2.-Lung function parameters in children with different patterns of wheezing

\begin{tabular}{|c|c|c|c|c|c|c|c|c|}
\hline Wheeze & $\begin{array}{c}\text { Subject } \\
\mathrm{n}\end{array}$ & $\begin{array}{l}\text { FVC } \\
\% \text { pred }\end{array}$ & $\begin{array}{l}\text { FEV1 } \\
\% \text { pred }\end{array}$ & $\begin{array}{c}\text { FEV1 } \\
\% \text { FVC }\end{array}$ & $\begin{array}{l}\text { PEF } \\
\% \text { pred }\end{array}$ & $\begin{array}{l}\text { MEF75 } \\
\% \text { pred }\end{array}$ & $\begin{array}{l}\text { MEF50 } \\
\% \text { pred }\end{array}$ & $\begin{array}{l}\text { MEF25 } \\
\% \text { pred }\end{array}$ \\
\hline None & 516 & $100.7 \pm 12.1$ & $100.9 \pm 11.9$ & $92.9 \pm 5.8$ & $102.0 \pm 20.2$ & $102.2 \pm 20.2$ & $103.2 \pm 22.8$ & $106.3 \pm 35.1$ \\
\hline Transient early & 200 & $100.3 \pm 12.8$ & $99.3 \pm 12.3$ & $91.9 \pm 6.2$ & $100.4 \pm 19.7$ & $100.1 \pm 20.9$ & $98.9 \pm 24.2 *$ & $101.2 \pm 36.4$ \\
\hline Late onset & 42 & $97.0 \pm 11.0$ & $94.1 \pm 12.2^{* * *}$ & $90.0 \pm 8.2 *$ & $93.8 \pm 14.4^{*}$ & $93.1 \pm 15.1^{* * *}$ & $87.4 \pm 21.6^{* * *}$ & $90.6 \pm 35.4 * *$ \\
\hline Persistent & 39 & $102.4 \pm 10.9$ & $96.5 \pm 9.3^{* *}$ & $87.8 \pm 6.8 * * *$ & $97.1 \pm 20.3$ & $93.8 \pm 20.2^{*}$ & $84.8 \pm 20.7^{* * *}$ & $76.0 \pm 30.2 * * *$ \\
\hline Current $^{\#}$ & 81 & $99.6 \pm 11.2$ & $95.3 \pm 10.9^{* * *}$ & $89.0 \pm 7.6^{* * *}$ & $95.4 \pm 17.5^{*}$ & $93.4 \pm 17.7^{* * *}$ & $86.1 \pm 21.1^{* * *}$ & $83.6 \pm 33.6^{* * *}$ \\
\hline
\end{tabular}

Data are presented as mean \pm SD. FVC: forced vital capacity; FEV1: forced expiratory volume in one second; PEF: peak expiratory flow; MEF75, MEF50 and MEF25: maximal expiratory flow when 75,50 and $25 \%$ of the FVC remains to be exhaled; $\%$ pred: percentage of the predicted value. ${ }^{*}$ : including "persistent" and "late-onset" wheezers. *, **, ***: $\mathrm{p}<0.5, \mathrm{p}<0.01, \mathrm{p}<0.001$ versus nonwheezers; ${ }^{\natural} \mathrm{p}<0.5$ versus persistent wheezers. 


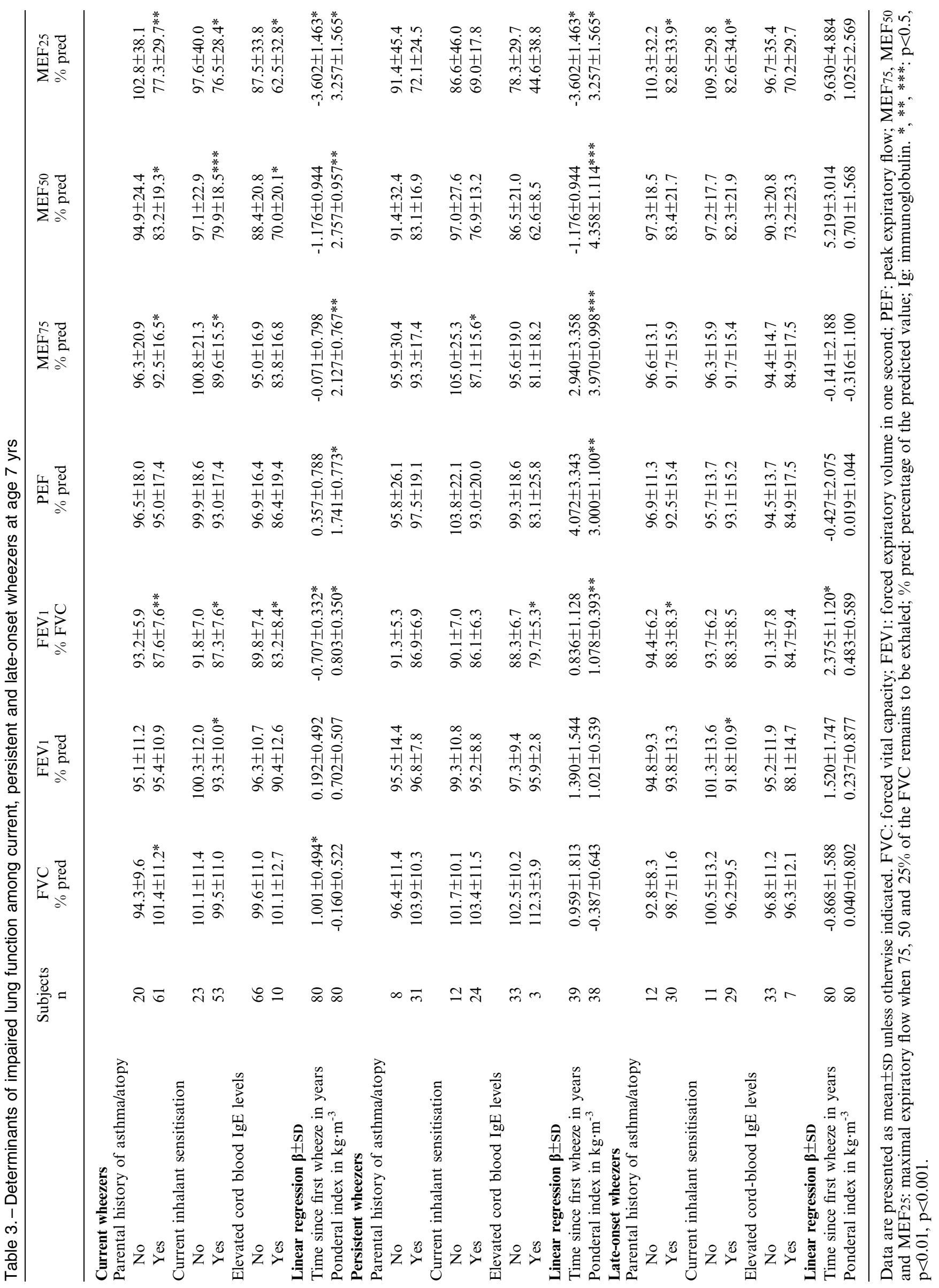


Table 4. - Further determinants of lung function among current wheezers at age 7 yrs: severity

\begin{tabular}{|c|c|c|c|c|c|c|c|c|}
\hline & $\begin{array}{c}\text { Subjects } \\
n\end{array}$ & $\begin{array}{l}\text { FVC } \\
\% \text { pred }\end{array}$ & $\begin{array}{l}\text { FEV1 } \\
\% \text { pred }\end{array}$ & $\begin{array}{c}\text { FEV1 } \\
\% \text { FVC }\end{array}$ & $\begin{array}{l}\text { PEF } \\
\% \text { pred }\end{array}$ & $\begin{array}{l}\text { MEF75 } \\
\% \text { pred }\end{array}$ & $\begin{array}{l}\text { MEF50 } \\
\% \text { pred }\end{array}$ & $\begin{array}{l}\text { MEF25 } \\
\% \text { pred }\end{array}$ \\
\hline \multicolumn{9}{|c|}{ Wheezing episodes $\mathrm{n}$} \\
\hline$\leqslant 3$ & 56 & $100.0 \pm 11.4$ & $96.4 \pm 11.5$ & $89.6 \pm 7.2$ & $97.4 \pm 18.0$ & $95.8 \pm 18.9$ & $88.5 \pm 21.5$ & $86.9 \pm 30.9$ \\
\hline$\geqslant 4$ & 25 & $98.8 \pm 10.9$ & $92.7 \pm 9.2$ & $87.5 \pm 8.2$ & $90.8 \pm 15.6$ & $88.0 \pm 13.3$ & $80.9 \pm 19.5$ & $76.1 \pm 38.6$ \\
\hline \multicolumn{9}{|c|}{ Awakening due to wheeze } \\
\hline No & 45 & $97.8 \pm 11.1$ & $93.0 \pm 9.9$ & $88.6 \pm 7.8$ & $92.7 \pm 18.3$ & $90.3 \pm 17.9$ & $83.1 \pm 19.5$ & $78.7 \pm 31.5$ \\
\hline Yes & 36 & $101.8 \pm 11.2$ & $98.2 \pm 11.6^{*}$ & $89.4 \pm 7.4$ & $98.7 \pm 16.0$ & $97.3 \pm 16.9$ & $89.9 \pm 22.6$ & $89.7 \pm 35.6$ \\
\hline \multicolumn{9}{|c|}{ Speech-limiting wheeze } \\
\hline No & 57 & $99.0 \pm 10.3$ & $94.7 \pm 10.7$ & $88.6 \pm 7.7$ & $97.0 \pm 18.1$ & $94.4 \pm 18.1$ & $86.0 \pm 23.1$ & $83.7 \pm 35.5$ \\
\hline Yes & 24 & $101.0 \pm 13.3$ & $96.8 \pm 11.6$ & $89.8 \pm 7.3$ & $91.6 \pm 15.5$ & $91.0 \pm 16.8$ & $86.5 \pm 15.8$ & $83.5 \pm 29.2$ \\
\hline \multicolumn{9}{|c|}{ Wheeze with exercise } \\
\hline No & 45 & $98.6 \pm 12.3$ & $96.6 \pm 12.6$ & $91.1 \pm 7.1$ & $97.2 \pm 18.1$ & $94.7 \pm 18.3$ & $89.6 \pm 22.4$ & $95.1 \pm 34.0$ \\
\hline Yes & 36 & $100.9 \pm 9.8$ & $93.6 \pm 8.2$ & $86.3 \pm 7.4^{* *}$ & $93.1 \pm 16.6$ & $91.8 \pm 17.0$ & $81.8 \pm 18.7$ & $69.2 \pm 27.3 * * *$ \\
\hline \multicolumn{9}{|c|}{ Wheeze with colds } \\
\hline No & 24 & $95.5 \pm 11.5$ & $93.3 \pm 10.3$ & $90.5 \pm 7.3$ & $90.4 \pm 13.9$ & $89.4 \pm 13.1$ & $88.4 \pm 15.8$ & $89.6 \pm 33.7$ \\
\hline Yes & 57 & $101.3 \pm 10.7^{*}$ & $96.1 \pm 11.1$ & $88.3 \pm 7.7$ & $97.5 \pm 18.5$ & $95.1 \pm 19.1$ & $85.2 \pm 23.0$ & $81.1 \pm 33.5$ \\
\hline
\end{tabular}

Data are presented as mean \pm SD. FVC: forced vital capacity; FEV1: forced expiratory volume in one second; PEF: peak expiratory flow; MEF75, MEF50 and MEF25: maximal expiratory flow when 75, 50 and 25\% of the FVC remains to be exhaled; $\%$ pred: percentage of the predicted value. $*, * *, * * *: \mathrm{p}<0.5, \mathrm{p}<0.01, \mathrm{p}<0.001$.

Table 5.-Determinants of impaired lung function among transient early wheezers at age 7 yrs $^{\#}$

\begin{tabular}{|c|c|c|c|c|c|c|c|c|}
\hline & $\begin{array}{c}\text { Subjects } \\
\mathrm{n}\end{array}$ & $\begin{array}{l}\text { FVC } \\
\% \text { pred }\end{array}$ & $\begin{array}{l}\text { FEV1 } \\
\% \text { pred }\end{array}$ & $\begin{array}{c}\text { FEV1 } \\
\% \text { FVC }\end{array}$ & $\begin{array}{l}\text { PEF } \\
\% \text { pred }\end{array}$ & $\begin{array}{l}\text { MEF75 } \\
\% \text { pred }\end{array}$ & $\begin{array}{l}\text { MEF50 } \\
\% \text { pred }\end{array}$ & $\begin{array}{l}\text { MEF25 } \\
\% \text { pred }\end{array}$ \\
\hline \multicolumn{9}{|c|}{ Maternal smoking during pregnancy } \\
\hline No & 135 & $100.1 \pm 13.5$ & $99.9 \pm 13.4$ & $92.6 \pm 5.8$ & $101.0 \pm 20.6$ & 101.0 & 101.6 & $104.9 \pm 37.1$ \\
\hline Yes & 49 & $100.5 \pm 11.0$ & $98.1 \pm 9.5$ & $90.5 \pm 6.8^{*}$ & $99.1 \pm 15.6$ & $97.8 \pm 15.6$ & $92.7 \pm 18.0^{*}$ & $94.0 \pm 34.2$ \\
\hline \multicolumn{9}{|c|}{ Lower respiratory tract infections $\leqslant 3$ yrs } \\
\hline$\leqslant 2$ & 160 & $101.1 \pm 13.4$ & $100.1 \pm 12.9$ & $91.9 \pm 6.3$ & $101.5 \pm 19.9$ & $101.3 \pm 20.8$ & $100.6 \pm 24.4$ & $102.9 \pm 38.0$ \\
\hline$\geqslant 3$ & 40 & $96.9 \pm 9.7 *$ & $96.3 \pm 9.0 *$ & $92.0 \pm 5.9$ & $96.3 \pm 18.7$ & $95.5 \pm 20.7$ & $92.3 \pm 22.5^{*}$ & $94.1 \pm 28.4$ \\
\hline
\end{tabular}

Data are presented as mean \pm SD. FVC: forced vital capacity; FEV1: forced expiratory volume in one second; PEF: peak expiratory flow; MEF75, MEF50 and MEF25: maximal expiratory flow when 75, 50 and $25 \%$ of the FVC remains to be exhaled; $\%$ pred: percentage of the predicted value. ${ }^{\#}: \mathrm{n}=199 .{ }^{*}: \mathrm{p}<0.5$.

current sensitisation to inhalant and indoor allergens (latter not shown separately), elevated cord-blood IgE levels and a low ponderal index at birth (table 3 ). A low ponderal index particularly influenced lung function in persistent wheezers, whereas time since first wheeze was more important in lateonset wheezers. Increased severity of asthma defined by number of wheezing episodes tended to be associated with a reduction in FEV1, MEF75\%, MEF $50 \%$ or MEF25\% (table 4). However, this was not significant. The question about "wheeze with exercise" was more appropriate in prediction of a reduction in FEV1 or FEV1/FVC. Furthermore, the ponderal index was more associated with FEV1 and MEF75\%, MEF50\% and MEF25\% than with birthweight.

\section{Transient early wheezers}

In transient early wheezers, frequent lower respiratory tract infections early in life and maternal smoking during pregnancy were significant determinants of lung function (table 5). Although maternal smoking was associated with a discrete reduction in FEV1 and MEF50\%, frequent lower respiratory tract infections during the first 3 yrs of life were associated with a moderate reduction in FVC, FEV1 and MEF50\%. However, the effects were small.

Environmental tobacco-smoke exposure at age 7 yrs (questionnaire) was not found to have any influence on pulmonary function in the different groups.

\section{Multivariate logistic regression analysis}

In the multivariate regression analysis, all influencing variables that were significant in the bivariate evaluation were included. Data were adjusted for study centre and season. "Current wheeze" and "wheeze ever" explained 14\% of differences for the ratio FEV1/FVC $\left(r^{2}=0.14, p<0.0001\right)$; all other influencing variables were of little explanatory value (data not shown).

\section{Discussion}

In the present study, it was shown that impaired lung function in 7-yr-old schoolchildren with various wheezing phenotypes is determined by different factors. In children with "early transient wheeze", maternal smoking was associated with a slight reduction in FEV1. Lower respiratory tract infections during the first 3 yrs of life were associated with a slight reduction in FVC. In "current wheezers" a low ponderal index at birth and atopy, i.e. sensitisation to indoor allergens, an atopic family history and elevated cord-blood IgE levels were associated with a reduction in FEV1 and MEF $25 \%$ and MEF50\%. However, differences remained small and mostly within the normal or subnormal range.

It was observed that $30 \%$ of the children who underwent lung function testing experienced wheezing illness at some time during the study period. However, the majority of 
children with early wheezing had a rather good prognosis and had lost their symptoms by the age of 7 yrs. MARTINEZ et al. [1] reported that approximately one-half of the children in their population-based epidemiological survey experienced wheezing episodes within the first 6 yrs of life, but that $60 \%$ of early wheezing children lost their symptoms by the age of 6 yrs.

\section{Possible confounders}

Although participating children were more likely to come from families of middle or higher class, there was no difference in parental history of asthma and atopy and so a relevant bias seems unlikely. Furthermore, the main purpose of the present investigation was to study determinants of impaired lung function in affected children and parental education was not a relevant confounder for lung function at the age of $7 \mathrm{yrs}$. Potential selection bias was assessed using stratified analysis. Asthma at age 7 yrs was not related to parental education, in contrast to the results of studies performed in the USA [19]. However, the present findings are in accordance with an Italian study reporting no relation between socioeconomic status and asthma prevalence [20].

\section{Determinants and predictors of poor lung function}

Current and past wheeze were found to be the strongest determinant of diminished lung function at the age of 7 yrs. Similar findings have been reported for older children [21].

It is striking that children with persistent or late-onset wheeze already show impairment of lung function at the age of $7 \mathrm{yrs}$. This is in accordance with the observations of MARTINEZ et al. [1]. However, for children with late-onset wheeze, there was only a trend toward a reduced maximal expiratory flow at functional residual capacity in the Tucson Study [1], whereas children with early wheeze showed impaired lung function in the first year of life which persisted at age 6 yrs. These children were 1 yr younger than the children of the MAS and the lung function testing methodology used was different.

Unfortunately, postbronchodilator results are not available at this age. Therefore, it is not possible to determine whether or not there are real changes in airway function, or whether there is simply reversible airway disease in children with wheeze and asthma. The fact that bronchial hyperresponsiveness in children with current wheeze is greater than in those with no wheeze or early transient wheeze [22] supports the notion that there is impairment of lung function due to prolonged inflammation in these children. However, data on the reversibility of obstructive airway disease will become available at the age of $10 \mathrm{yrs}$.

The time of onset of disease was a major determinant in the children with late-onset wheeze. However, a significant association between onset and severity of asthma, the latter defined as in table 3 (data not shown), could not be found. One possible explanation might be that there were no children with severe asthma, and early antiasthmatic therapy may have influenced lung function. Owing to the structure of the questionnaire, antiasthmatic therapy was incompletely registered.

When looking for association of questions with "severity" of asthma defined as reduction in FEV1/FVC or MEF $25 \%$, "wheeze with exercise" seemed to be more sensitive than "number of wheezing episodes".

There was no significant effect of passive smoking on lung function parameters in either healthy or asthmatic children. Other groups report diminished FEV1, especially in 8-yr-old females who have been exposed to environmental tobacco smoke [23].

\section{Atopy and wheezing}

"Current wheeze" was associated with atopic phenotype and $70 \%$ of the children with asthma symptoms at age $7 \mathrm{yrs}$ showed specific sensitisation to inhalant allergens (in the group of late-onset wheezers, $75 \%$ ). Other authors also report persistent wheezing associated with an atopic family history $[24,25]$, but, in these studies, lung function testing was not performed. Lung function in children with "current wheeze" was also influenced by cord-blood IgE levels. This may reflect the association between specific sensitisation and cord-blood IgE levels [26]. Specific sensitisation to inhalant allergens, especially indoor allergens, is associated with an increased risk of asthma [27], impaired baseline lung function and increased bronchial hyperreactivity [22]. However, it can be assumed that elevated levels of specific serum IgEs above the cut-off of $0.35 \mathrm{kU} \cdot \mathrm{L}^{-1}$ do not necessarily imply that the asthma is atopic. Repeated population surveys of the prevalence of respiratory symptoms have been carried out in the UK and have shown increases in all preschool wheezing disorders (including viral wheeze) [28]. Similar trends were seen in schoolchildren in Norway [29]. Hence factors unrelated to atopy are also implicated in the changing epidemiology of wheeze in childhood.

Are endogenous factors more important than exogenous factors in the development of asthma and impaired lung function?

The determinants of baseline lung function in current wheezers, however, explain only $\sim 30 \%$ of differences in lung function parameters. Considering the fact that a maternal history of asthma has a major impact on the development of asthma in the child, it seems likely that congenitally determined local airway susceptibility, e.g. smaller airways, structural or functional abnormalities in the epithelium and decreased foetal lung development, provide a major basis for asthma and impaired lung function. Children at risk of development of chronic asthma and impairment of lung function seem to be those children with early onset of obstructive airway symptoms, an atopic family history and early and persistent sensitisation to food and inhalant allergens [30-32] and are probably the candidates for early anti-inflammatory therapy in order to avoid structural damage, remodelling and ongoing impairment of lung function.

In contrast, transient early wheeze was not related to atopy and this subgroup showed only a slight reduction in MEF50\% at age $7 \mathrm{yrs}$, which is in contrast to the results of other authors $[1,2]$. Lung function parameters in children with transient early wheezing were influenced by maternal smoking during pregnancy, as reported by other authors $[1,33]$, and increased episodes of lower respiratory tract infection. In the MAS, nonwheezing lower respiratory tract infections during the first year of life constituted no major risk for subsequent wheeze up to the age of $7 \mathrm{yrs}$, whereas lower respiratory tract infections followed by wheezing episodes showed a strong positive association, thus supporting the notion of reverse causation.

MARTINEZ et al. [34] could show reduced pulmonary function, as measured using the rapid thoracoabdominal compression technique (maximal expiratory flow at functional residual capacity) as an indicator of small airway function, shortly after birth. At this time-point, no lower respiratory tract infection had occurred and so congenitally smaller airways may 
predispose children to wheezing illness early in life. This conclusion is supported by a British study showing that bronchial hyperresponsiveness during the neonatal period was a risk factor for wheezing in infancy [35].

In a longitudinal birth cohort study performed in New Zealand, increased foetal growth was related to an increased risk of asthma and atopy. Birth length and birthweight were significantly associated with total IgE levels at 11 yrs [9]. The present findings with regard to lung function show that children of low birthweight are more likely to show impaired lung function, which is in accordance with the results of other authors [36]. However, premature newborns below 37 weeks of gestation and $2 \mathrm{~kg}$ birthweight were not included in the MAS study.

In summary, early transient, late onset and persistent wheeze reflect different disease entities demanding different therapeutic procedures. Although the first group seems to have a rather good prognosis, the other two groups show early reduction in expiratory flow values due to allergic inflammation and genetically determined structural and functional abnormalities, possibly requiring antiasthmatic therapy early in life.

Acknowledgements. The authors would like to thank the Multicentre Allergy Study Group: V. Wahn, M. Groeger (Düsseldorf); F. Zepp, I. Bieber (Mainz); U. Tacke (Freiburg); C-P. Bauer (Geisach); K-E. Bergmann (Berlin); and the nurses P. Wagner (Berlin), G. Leskosek (Düsseldorf), R. Mayrl (Munich), B. Hampel (Mainz), M. Götz (Freiburg); and the statistician G. Edenharter. The authors are indebted to the language editor $\mathrm{R}$. Holmes (Berlin) and E. von Mutius (Munich).

\section{References}

1. Martinez FD, Wright AL, Taussig LM, Holberg CJ, Halonen M, Morgan WJ. Asthma and wheezing in the first six years of life. New Engl J Med 1995; 332: 133-138.

2. Strachan DP, Butland BK, Anderson HR. Incidence and prognosis of asthma and wheezing illness from early childhood to age 33 in a national British cohort. BMJ 1996; 312: 1195-1199.

3. Baker DJP, Godfrey KM, Fall C, Osmond C, Winter PD, Shaheen SO. Relation of birth weight and childhood respiratory infection to adult lung function and death from chronic obstructive airway disease. BMJ 1991; 303: 671-675.

4. Taussig LM, Landau LI, Godfrey S, Arad I. Determinants of forced expiratory flows in newborn infants. $J$ Appl Physiol 1982; 53: 1220-1227.

5. Hanrahan JP, Tager IB, Segal MR, et al. The effect of maternal smoking during pregnancy on early infant lung function. Am Rev Respir Dis 1992; 145: 1129-1135.

6. Barber K, Mussin E, Taylor DK. Fetal exposure to involuntary maternal smoking and childhood respiratory disease. Ann Allergy Asthma Immunol 1996; 76: 427-430.

7. Demissie K, Ernst P, Joseph L, Becklake MR. Birthweight and preterm birth in relation to indicators of childhood asthma. Can Respir J 1997; 4: 91-97.

8. Chan KN, Elliman A, Bryan E, Silverman M. Respiratory symptoms in children with low birth weight. Arch Dis Child 1989; 64: 1294-1304.

9. Leadbitter P, Pearce N, Cheng S, et al. Relationship between fetal growth and the development of asthma and atopy in childhood. Thorax 1999; 54: 905-910.

10. Strope GL, Stewart PW, Henderson FW, Ivins SS, Stedman HC, Henry MM. Lung function in school-age children who had mild lower respiratory illnesses in early childhood. Am Rev Respir Dis 1991; 144: 655-662.

11. Henderson FW, Stewart PW, Burchinal MR, et al.
Respiratory allergy and the relationship between early childhood lower respiratory illnesses and subsequent lung function. Am Rev Respir Dis 1992; 145: 283-290.

12. Welliver RC, Duffy L. The relationship of RSV-specific immunoglobulin $\mathrm{E}$ antibody responses in infancy, recurrent wheezing, and pulmonary function at age 7-8 years. Ped Pulmonol 1993; 15: 19-27.

13. Sigurs N, Bjarnason R, Sigurbergsson F, Kjellman B, Bjorksten B. Asthma and immunoglobulin E antibodies after respiratory syncytial virus bronchiolitis: a prospective cohort study with matched controls. Pediatrics 1995; 95 : 500-505.

14. Stein RT, Sherrill D, Morgan WJ, et al. Respiratory syncytial virus in early life and risk of wheeze and allergy by age 13 years. Lancet 1999; 354: 541-545.

15. Bergmann RL, Bergmann KE, Lau-Schadendorf $\mathrm{S}$, et al. Atopic diseases in infancy. The German Multicenter Atopy Study (MAS-90). Pediatr Allergy Immunol 1994; 5: Suppl. 1, $19-25$.

16. Asher MI, Keil U, Anderson HR, et al. International Study of Asthma and Allergies in Childhood (ISAAC): rationale and methods. Eur Respir J 1995; 8: 483-491.

17. Quanjer PH, Tammeling GJ, Cotes JE, Pedersen OF, Peslin $\mathrm{R}$, Yernault JC. Lung volumes and forced ventilatory flows. Eur Respir J 1993; 6: Suppl. 16, 5-40.

18. Anon. NHLBI workshop summary. Assessment of lung function and dysfunction in studies of infants and children. Am Rev Respir Dis 1993; 148: 1105-1108.

19. Kattan M, Mitchell H, Eggleston P, et al. Characteristics of inner-city children with asthma: the National Cooperative Inner-City Asthma Study. Pediatr Pulmonol 1997; 24: 253-262.

20. SIDRIA Collaborative Group. Asthma and respiratory symptoms in 6-7 year old Italian children: gender, latitude, urbanization and socioeconomic factors. Eur Respir J 1997; 10: $1780-1786$.

21. Weiss ST, Tostecon TD, Segal MR, Tager IB, Redline S, Speizer FE. Effects of asthma on pulmonary function in children: a longitudinal population-based study. Am Rev Respir Dis 1992; 145: 58-64.

22. Niggemann B, Illi S, Madloch C, et al. Histamine challenges discriminate between symptomatic and asymptomatic children. Eur Respir J 2001; 17: 246-253.

23. Tager IB, Weiss ST, Munz A, Rosner B, Speizer FE. Longitudinal study of the effects of maternal smoking on pulmonary function in children. $N$ Engl J Med 1983; 309: 699-703.

24. Clough JB, Keeping KA, Edwards LC, Freeman WM, Warner JA, Warner JO. Can we predict which wheezy infants will continue to wheeze? Am J Respir Crit Care Med 1999; 160: 1473-1480.

25. Rusconi F, Galassi C, Corbo GM, et al. Risk factors for early, persistent, and late-onset wheezing in young children. Am J Respir Crit Care Med 1999; 160: 1617-1622.

26. Edenharter G, Bergmann RL, Bergmann KE, et al. Cordblood-IgE as a risk factor and predictor for atopic disease. Clin Exp Allergy 1998; 28: 671-678.

27. Lau S, Illi S, Sommerfeld C, et al. Early exposure to housedust mite and cat allergens and development of childhood asthma: a cohort study. Lancet 2000; 356: 1392-1397.

28. Kuehni CE, Davis A, Brooke AM, Silverman M. Are all wheezing disorders in very young (preschool) children increasing in prevalence? Lancet 2001; 357: 1821-1825.

29. Nystad W, Magnus P, Gulsvik A. Increasing risk of asthma without other atopic diseases in school children. Eur $J$ Epidemiol 1998; 14: 247-252.

30. Kulig M, Bergman R, Tacke U, Wahn U, GuggenmoosHolzmann I. Long-lasting sensitisation to food during the first two years precedes allergic airway disease. Pediatr Allergy Immunol 1998; 9: 61-67.

31. Tariq SM, Matthews SM, Hakim EA, Arshad SH. Egg allergy in infants predicts respiratory allergic disease by 4 years of age. Pediatr Allergy Immunol 2000; 11: 162-167. 
32. Illi S, von Mutius E, Lau S, et al. The pattern of atopic sensitisation is associated with asthma in childhood. $J$ Allergy Clin Immunol 2001; 108: 709-714.

33. Stick SM, Burton PR, Gurrin L, Sly PD, LeSouef PN. Respiratory function in newborn infants: effects of maternal smoking during pregnancy and a family history of asthma. Lancet 1996; 348: 1060-1064.

34. Martinez FD, Morgan WJ, Wright AL, Holberg CJ, Taussig LM. Diminished lung function as a predisposing factor for wheezing respiratory illness in infants. N Engl J Med 1988; 319: 1112-1117.

35. Clarke JR, Salmon B, Silverman M. Bronchial responsiveness in the neonatal period as a risk factor for wheezing in infancy. Am J Respir Crit Care Med 1995; 151: 14341440.

36. Lewis S, Richards D, Bynner J, Butler N, Britton J. Prospective study of risk factors for early and persistent wheezing in childhood. Eur Respir J 1995; 8: 349-356. 